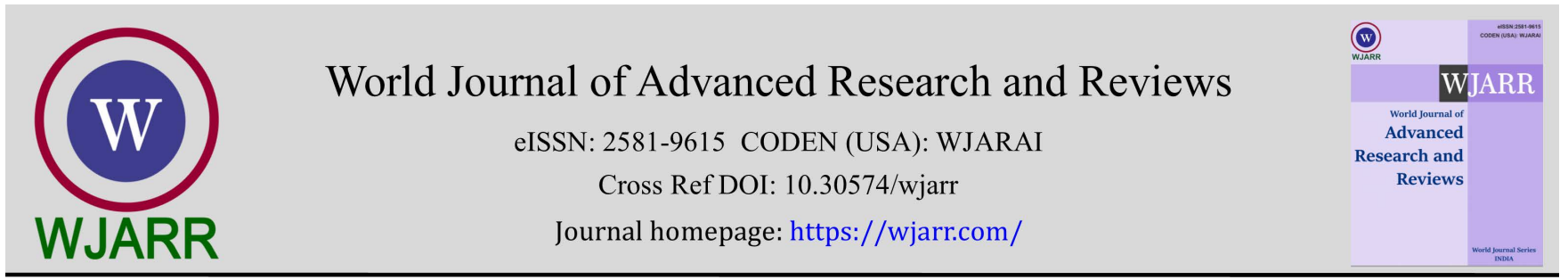

(RESEARCH ARTICLE)

\title{
Effectiveness of Community-Based Psychosocial Services for Individuals with Mental Health Problems in Elbasan city, Albania
}

\author{
Flutra Musta * and Monika Bogdanova \\ Department of Social Work, Faculty of Pedagogy, Sofia University "St. Kliment Ohridski", Sofia, Bulgaria.
}

World Journal of Advanced Research and Reviews, 2021, 10(01), 279-288

Publication history: Received on 17 March 2021; revised on 20 April 2021; accepted on 22 April 2021

Article DOI: https://doi.org/10.30574/wjarr.2021.10.1.0176

\begin{abstract}
An integrated system of mental health services means a network of services at the regional level, which responds to the needs of the population it covers for inclusive services, with a focus on community services. This category of services includes all those services that focus on the objectives and their functioning have the diagnosis, treatment and rehabilitation of persons with mental disorders, as well as the prevention of these disorders and the promotion of positive mental health.

Psychosocial interventions undoubtedly play an important role in the treatment of individuals with mental health problems in addition to drug treatment.

Therefore, the study includes measuring the satisfaction of individuals with mental health problems and the effectiveness of community services and in particular that of community-based psychosocial interventions [3]. The study aims to determine the level of patient satisfaction of Community Health Centers mental and mainly in the city of Elbasan. For the realization of the study was used the quantitative method combined with the qualitative method. The patients of this center were randomly selected as a sample in the time frame of 3 months. As an instrument in the questionnaire are used open and closed questions.
\end{abstract}

The results of the study show that patients are generally satisfied with the services provided to them by the center team and there is still room for improvement of these services.

Keywords: Psychosocial Rehabilitation; Mental Health; Treatment; Intervention; Community Services

\section{Introduction}

Community Mental Health Centers (CMHC) are specialized outpatient mental health services that provide multidisciplinary / multidimensional services at the community level. They are part of specialty polyclinics, although they may be physically separated from them $[1,2]$.

CMHC - carries out identification, diagnostic, treatment and rehabilitation activities for every person suffering from mental disorders, as well as plays a role of preventing disorders and promoting positive mental health in a coverage area with a population ranging from 50000-150000 inhabitants and coordinates its activity with primary and secondary health care services, but also social services.

In accordance with the objectives and standards of functioning of Mental Health Services, CMHC is given functional autonomy in the respective coverage area [4].

*Corresponding author: PhD. Flutra Musta

Sofia University "St. Kliment Ohridski", Sofia, Bulgaria.

Copyright (c) 2021 Author(s) retain the copyright of this article. This article is published under the terms of the Creative Commons Attribution Liscense 4.0. 
CMHC, as they are specialized intermediary services, play the role of the main link in the referral system. Thus, referrals to the CMHC service are made by the family doctor, other specialized doctors, family members or the individual himself in cases of identification of a problem, or by secondary and tertiary care specialists, in cases of patients who need followup in community after leaving bed services. Also, CMHC is the main point of referral of patients who need hospitalization in mental health services with beds, except in cases of psychiatric emergencies that can be directed directly to the service with the nearest beds.

Each CMHC has a multidisciplinary team consisting of doctors, nurses, psychologists, social workers, and occupational therapists, who act in a coordinated manner, according to the relevant protocols for maintaining and improving mental health. Professionals with pedagogical and rehabilitative competencies, such as speech therapists, developmental therapists or other specialists can join the team. Teamwork aims to use the most efficient human and professional resources of service, valuing the contribution of each employee through specific tasks or responsibilities, as well as maintaining a fair relationship of interdependence and operational autonomy. Teamwork is realized through the systematic circulation of information respecting the principle of maintaining professional secrecy, development of therapeutic projects through multidisciplinary actions, coordination of interventions in cooperation between different professional figures, continuous education of the team.

\subsection{CMHC responds to the needs for multi-disciplinary mental health services, such as:}

- $\quad$ case identification and early detection of the disease;

- assessment of the health and socio-economic situation of the patient by different members of multidisciplinary team;

- complex diagnosis of mental disorders and other health circumstances;

- $\quad$ assessment of individual needs for further support and intervention;

- medication and psychological treatment;

- $\quad$ psycho-social rehabilitation;

\subsection{Mental health and psychosocial support}

According to the World Health Organization (WHO), health is a state of complete physical, mental and social well-being, and not just the absence of conditions or diseases. So, to achieve or maintain this state, you can use different strategies within different areas. One of these spaces of knowledge and application is, in fact, psychosocial intervention.

Before we expand on this, it is important that we all understand what psychosocial intervention is. According to Alvis (2009) [4], psychosocial intervention is a process that aims to increase the development capacity of human beings, their families and communities. This allows subjects to exercise control and power over their individual and social environment. In that way, it increases the well-being and quality of life of people, training and providing them with individual tools that will allow them to face and solve problems, as well as make changes in their social environment. Psychosocial intervention is performed through two interrelated contexts: psychological and social. The individual must begin by considering his or her entire social environment and that with which they interact. When intervening, it is important to remember how important the role of primary care professionals actually is. This is the closest and most accessible service. From there, experienced professionals will evaluate and transfer the patient. One thing to keep in mind is that the coordinated effort of different professionals is essential to achieving the goals. Pharmacological can be important, (always prescribed by a professional, of course), it is important not to forget about the importance of psychosocial intervention. Psychosocial support should include social support, monitoring, companionship and social rehabilitation. The main objective of this practice is to contribute to the autonomy of an individual suffering from a mental illness. Psychosocial support services help people with severe mental illness to build skills for manage their mental illnesses, improve their relationships with family and others, and increase social and economic participation.

\subsection{Psychosocial intervention in people with mental illness includes:}

- Activities related to their living situation: supervision,

- Assistance in finding accommodation, etc.

- Daily activities.

- Support for daily instrumental activities.

- Supervision and training for medication administration.

- Guidelines when working with the organization and time management.

- Training for social and family life.

- Socio-legal advice. 
For this and other reasons, it is important to encourage those who may need to visit a mental health professional and help them understand how beneficial psychosocial intervention can be for them.

Psychosocial treatments include various types of psychotherapy and social and vocational training and aim to provide support, education and guidance for people with mental illness and their families. Psychosocial treatments are an effective way to improve the quality of life for individuals with mental illness and their families. They can lead to fewer hospitalizations and fewer difficulties at home, at school and at work.

\subsection{Types of psychosocial treatments [5]}

\subsubsection{Psychotherapy}

Often called conversation therapy, psychotherapy is when a person, family, couple or group sits down and talks to a therapist or other mental health provider. Psychotherapy helps people learn about their moods, thoughts, behaviors, and how they affect their lives. They also offer ways to help restructure thinking and respond to stress and other conditions.

\subsubsection{Psychoeducation}

Psychological education teaches people about their illness and how they will receive treatment. Psychoeducation also includes education for family and friends where they learn things like coping strategies, problem-solving skills, and how to recognize the signs of relapse. Family psychoeducation can often help alleviate tensions at home, which can help the person experiencing mental illness recover. Many of NAMI's educational programs are examples of psychoeducation.

\subsubsection{Self-Help and Support Groups}

Self-help and support groups can help address feelings of isolation and help people gain knowledge about their mental health status. Support group members can share frustrations, successes, referrals to specialists, where they can find the best community resources and tips on what works best when trying to recover. They also make friends with other group members and help each other on the path to healing. As with psychoeducation, families and friends can also benefit from their support groups.

\subsubsection{Psychosocial Rehabilitation}

Psychosocial rehabilitation helps people develop the social, emotional and intellectual skills they need in order to live happily with the least professional help they can manage. Psychosocial rehabilitation uses two intervention strategies: learning coping skills so that they are more successful in dealing with a stressful environment and developing resources that reduce future stressors. Treatments and resources vary from case to case, but may include medication management, psychological support, family counseling, vocational and independent living training, housing, on-the-job training, educational assistance, and social support.

\subsubsection{Supported employment}

Work can be an essential step on the path to well-being and recovery, but the challenges that come with mental illness can make it more difficult. However, there are programs specifically designed to help with job readiness, job search, and job support.

\subsubsection{Vocational Rehabilitation}

VR provides career counseling and job search assistance for people with disabilities, including mental illness. VR program structures vary from state to state. To learn more about your specific state program, visit your state's VR agency. Employment programs are evidence-based programs that help people with mental illness find jobs that match their individual strengths and interests. Once an individual finds a job, employment programs provide ongoing support to help the person succeed in the workplace.

\subsubsection{Case management}

Living well with a complicated health condition (physical or mental) may require working with a number of medical providers and support resources. Case management can help individuals coordinate these services. A case manager has knowledge of local medical facilities, housing opportunities, employment programs, and social support networks. He or she is also familiar with many payment options, including local, state, and federal aid programs. This person can play an important role in helping individuals in need or your family members receive the best possible treatment. A case 
manager will assess needs and suggest what resources are available, explain the process and apply for services. A case manager keeps in touch with individuals to ensure that this individual continues to meet treatment needs. Case managers are professionals with certification in case management or a degree in social work. A good case manager cannot guarantee that he or she will take advantage of every resource to which individuals will apply, but he or she should definitely keep them informed and are good listeners of their concerns.

\section{Material and methods}

Mixed research methods have been used to carry out the study. Creswell, 2003 emphasizes that through the mixed method researchers better understand the research problem, converges quantitative and qualitative data with the aims to provide a comprehensive analysis of the research problem [6]. In this way the researcher collects both forms of data at the same time during the study and then integrates the information into the interpretation of the overall results. Quantitative and qualitative instruments or methods are intertwined during the study.

A structured questionnaire with open and closed questions was used in the study. The questions in the first part focused on demographic data such as age, gender, education and current status of the respondents. Patients' expectations for this professional regarding the service received, the way of treatment, for the recommended treatment. Then we continue with the questions constructed about the role and importance of psychosocial services and the effectiveness of their work as a team, and in the last part the questionnaire is constructed from questions about the function and role of social worker in particular in this mental health institution and the satisfaction that patients show in meetings or from the services received by this professional.

The study is also based on the study of various foreign and domestic literatures. Sampling includes patients who suffer from mental health problems and who at the time of the study presented for a meeting or re-meeting with the professionals of the Mental Health Center in Elbasan in the period September 2020-December 2020. A total of 150 patients were surveyed who were randomly selected and we can say that there are patients who agreed to be surveyed after every step of the study was explained to them and they were assured of complete confidentiality.

The purpose of the study is to analyze the satisfaction of individuals suffering from mental health problems related to community services and in particular community-based psycho-social services for this target group. The study was conducted in the community center of mental health in Elbasan. This center offers services for children, adolescents and adults. The organization of this service consists of 9 professionals who are (Table 1):

Table 1 Organization staff

\begin{tabular}{|l|l|l|l|l|}
\hline Psychiatrist & Psychopediatricians & Social workers & Psychologists & Nurses \\
\hline 2 & 1 & 1 & 2 & 3 \\
\hline
\end{tabular}

\section{Results and discussion}

Of the participants included in the study with a differentiated percentage, women dominate with $61 \%$, versus $39 \%$ of the other gender; this is also the fact that men refused to be part of the study

The highest percentage of patients belong to the age group 28-37 years (31\%) followed by the age group 58 years old (22\%), the age group 38-47 years with (19\%), the age group 18-27 years (11\%) and last age group $48-57$ years $(17 \%)$.

Most of the subjects, $44 \%$ were with $8 / 9$ year education, $35 \%$ with secondary education, $12 \%$ with higher education, 7\% primary education (Figure 1). 


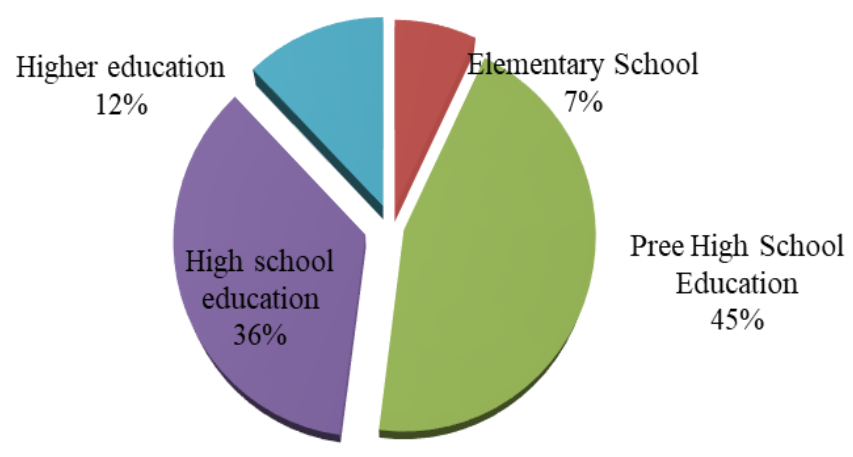

Figure 1 Education

Approximately half of the study participants $48 \%$ were married, $37 \%$ were single, $15 \%$ divorced (Figure 2 ).

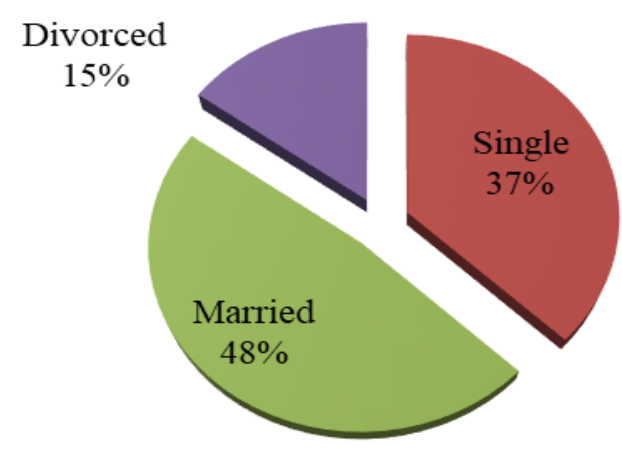

Figure 2 Status of respondents

$29 \%$ of respondents stated that they have a period of 6-10 suffering from mental health problems, $24 \% 2-5$ years, $14 \%$ belong to the age group less than one year, 13\% have more than 10 years treated for mental health problems, $7 \%$ do not remember how long they are treated and $10 \%$ admit that although they have been suffering from mental health for some time, they have never contacted the CMHC.

According to the regulation of CMHC, individuals with mental health problems seem to appear once every three months in CMHC to re-consult with a psychiatrist, as well as with the other team of the center, this for those individuals whose health condition has been stabilized in this last three months. But this does not mean that these individuals do not seek faster the services of CMHC staff (Figure 3)

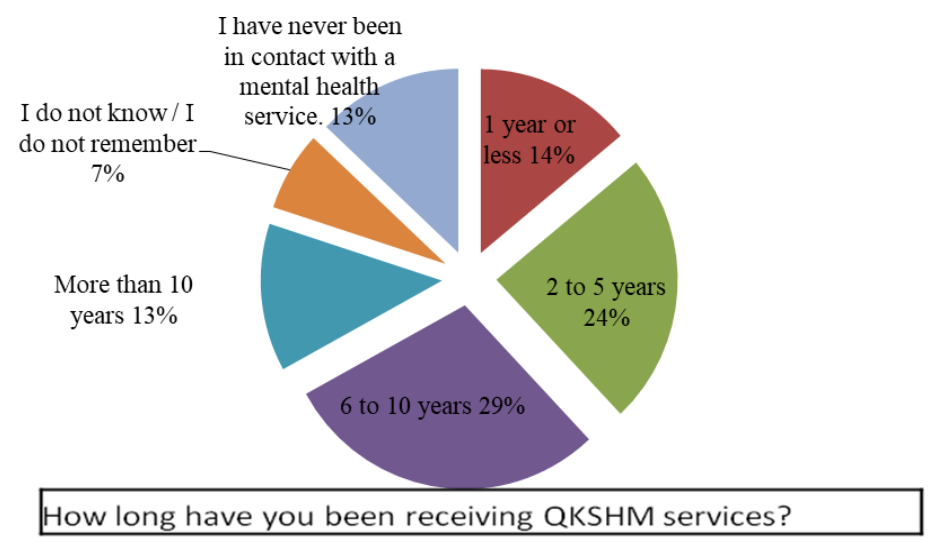

Figure 3 Chronology of the disease of the respondents

Consultations can be done once a week, once a month, but always based on the progress of individuals with mental health problems and according to the re-appointment decided by the staff based on the latest findings on the patient's 
assessment. Based on the answers The data of the respondents show that the individuals who were selected as a sample, $33 \%$ of them stated that they returned to receive the services of CMHC after three months from the last consultation, 41\% after 4-6 months, 21\% state that they presented in these centers after 6 months, $2 \%$ are returned within a week and $3 \%$ within a month (Figure 4 ).

98\% of respondents have accepted the fact that they have met with a psychiatrist and $2 \%$ have not met him at KCSM this may be due to the fact that in this KCSM three psychiatrists practice their profession and probably at that time did not have met their doctor who has done the follow-up or the last meeting.

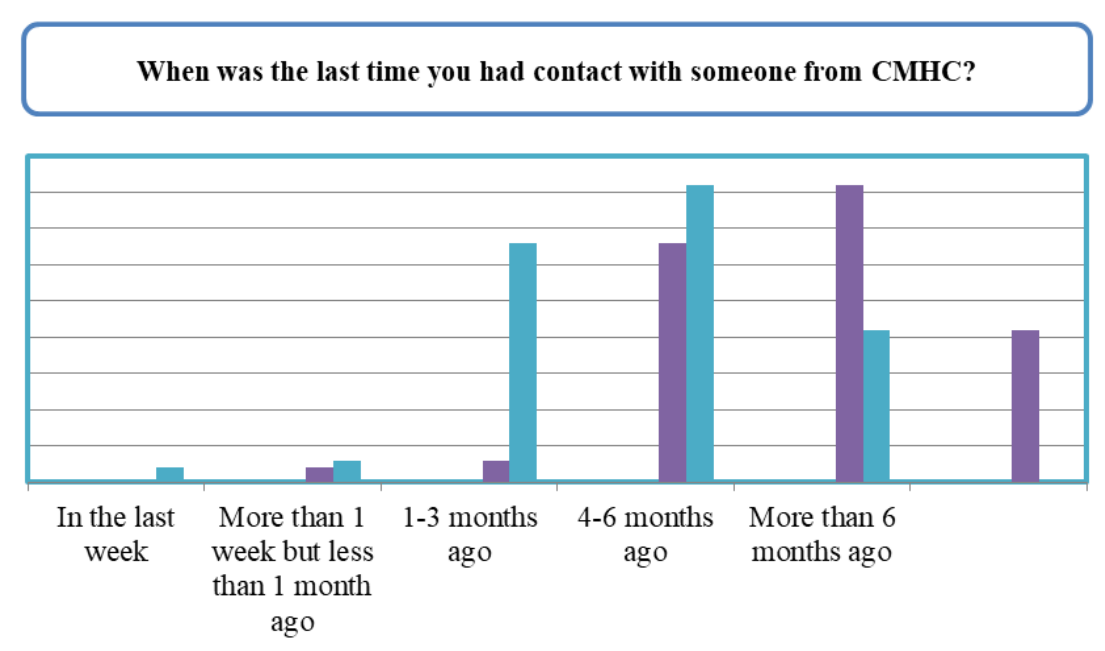

Figure 4 Rhythm of consultations at CMHC Elbasan for respondents

This is shown by the answers received where $58 \%$ of respondents testify that the re-appointment was done with the same psychiatrist, $17 \%$ confess that they were not followed by the same psychiatrist this can to be a preferential issue where $25 \%$ said that in the next contact they met only with other KCSHM professionals such as social worker, psychologist or nurse (Figure 5).

\section{The last time you had an appointment with a specialist doctor, was it?}

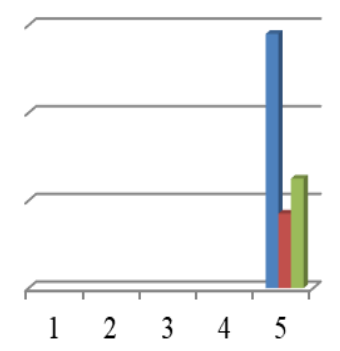

-With the same psychiatrist twice

- With different psychiatrists

- Other health professionals (eg a social worker, occupational therapist, or psychologist)
$58 \%$

$25 \%$

$17 \%$

Figure 5 Consultation with a psychiatrist

From the last meeting with the psychiatrist $70 \%$ of the respondents said that they were respected by the latter and listened carefully while $18 \%$ expressed to some extent, while $12 \%$ have dissatisfaction. Although $82 \%$ of them are listened carefully to the doctor about the concerns displayed $10 \%$ have preferred the alternative to some extent, while $8 \%$ think that the doctor has not listened to the end but this does not mean that the doctor has not shown respect but that a timeline should be respected, to leave the queue for other patients and at the same time to avoid the dependence that these patients create on these professionals. 
Regarding the consultations with the rest of the NCMS team, $79 \%$ of the respondents say that they have met with other professionals and another $21 \%$ confess that they have not met. This may be their personal choice or lack of information (Figure 6)

about the role of other employees and for the range of services they can offer.88\% of them confess that they have met with the social worker where surprisingly the same percentage of $88 \%$ results for the psychologist, probably due to the fact that both of these professionals practice the profession there in the same office and perhaps in this way have met both, and $12 \%$ of them say they have met other professionals who may be nurses.
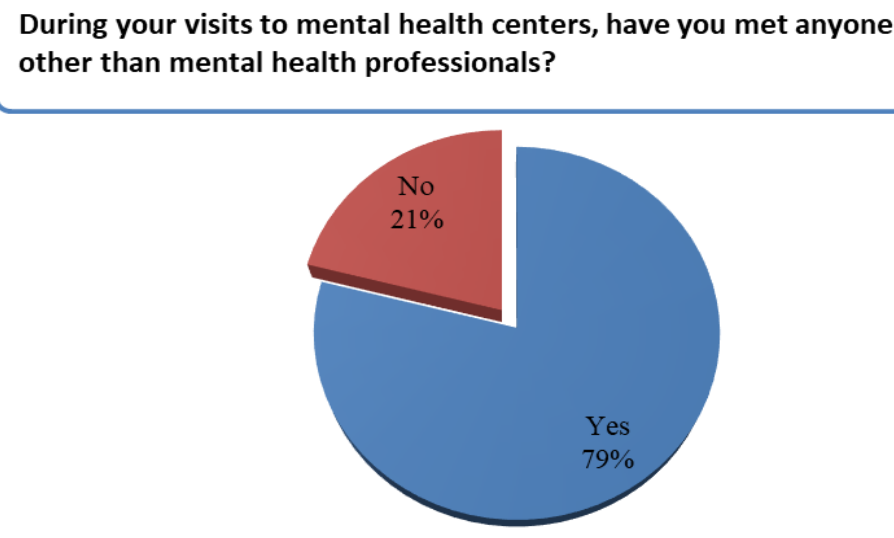

Figure 6 Consultation with other professionals

From the meeting with the part of the psychosocial team $73 \%$ of the respondents testify that they have been listened to carefully by these professionals about their concerns, $14 \%$ to some extent and $13 \%$ think that they have not been heard to the end. This is in order not to create dependence and to respect the time limit for each patient or individual who presents to KCSM to receive the relevant service.

Regarding the questions raised about the role of the social worker in particular $81 \%$ of the respondents say that they have received service from the social worker of the center, $10 \%$ of them do not know that there is a social worker, $7 \%$ do not know him, 2\% They think that they do not need the services of a social worker. From this meeting $79 \%$ think that they have been treated with dignity and respect, $15 \%$ express themselves to some extent while $6 \%$ express dissatisfaction with this meeting (Figure 7)

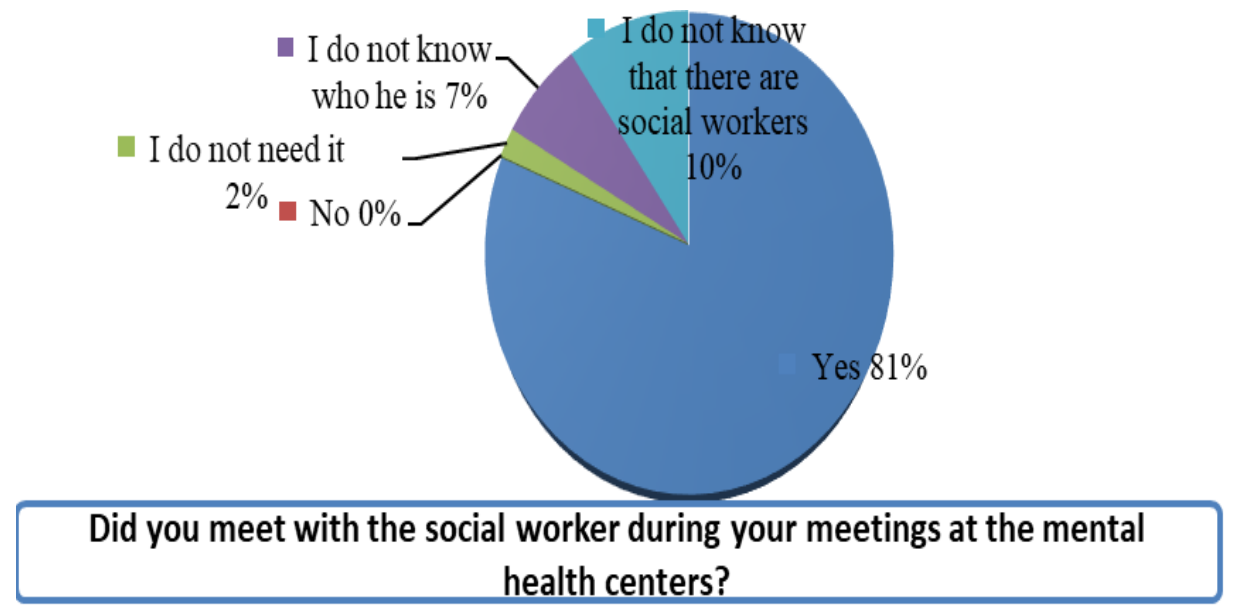

Figure 7 Meeting with the social worker

Regarding the referral for the meeting with the social worker, $57 \%$ say that it was the request of the social worker, $28 \%$ testify that it was a referral from a psychiatrist, $9 \%$ were referred by family or friends, and $6 \%$ admitted that it was a wish or their need for this meeting or service. The services that can be provided by the social worker in this institution 
are very diverse and very necessary to help individuals with mental health problems in their treatment and rehabilitation (Figure 8).

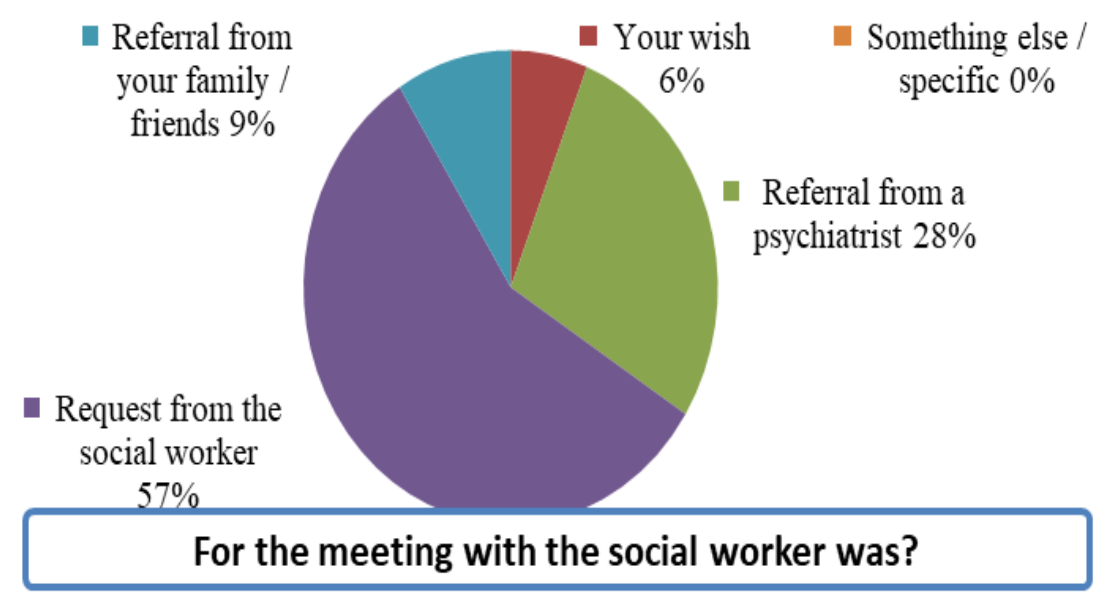

Figure 8 Request to meet with the social worker

For this reason $37 \%$ of respondents say that the service they received from the social worker was a referral for various benefits, $30 \%$ advice, and $18 \%$ admit that they were accompanied by a social worker to provide services in other institutions such as the municipality, employment offices, near social services offices, near professional courses offices, etc.

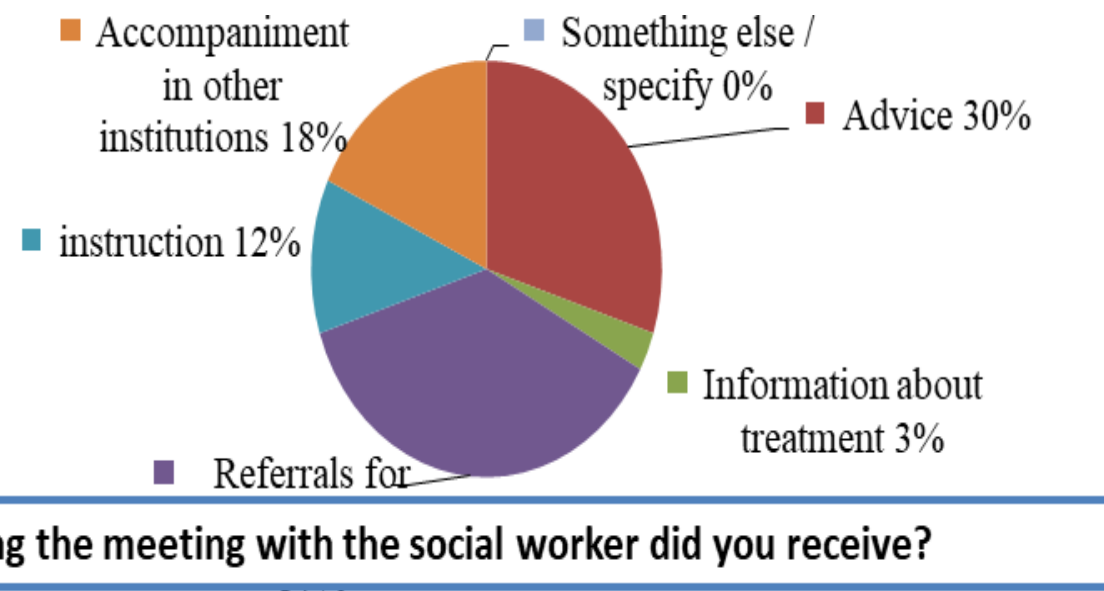

Figure 9 Services received by the social worker

Based on the experiences of meetings with the social worker, $97 \%$ of the respondents have expressed the desire to meet again and 3\% think that they do not need the service of the social worker. Of these $36 \%$ say that they have been referred by the social worker for economic assistance, $12 \%$ for the benefit of food packages from social services or various NGOs operating in the country for the categories in need, $27 \%$ of them have been provided assistance or referral for the benefit of reimbursement of treatment, $15 \%$ were referred directly to various NGOs, and $10 \%$ to other services. It remains to be mentioned that it is $0 \%$ referral for social housing and $0 \%$ referral for attending day care centers for mental health due to the fact that in terms of social housing is the municipality that deals with these issues and the review of these cases and the second in the Elbasan city are missing day care centers for mental health (Figure 10). 


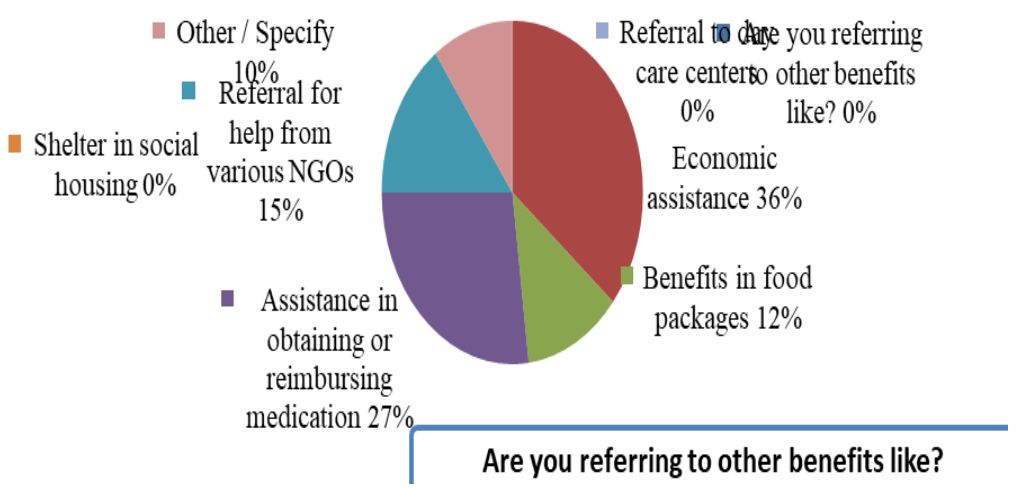

Figure 10 Importance for the role of social worker.

Regarding the individual treatment plan for each of the respondents $38 \%$ of them understand what an individual treatment plan can be, 29 preferred to express it to some extent, $22 \%$ do not understand and $11 \%$ of them think that they do not have an individual treatment plan. $61 \%$ of them say that they agreed with the form and manner of their treatment, $33 \%$ to some extent and $6 \%$ do not agree.

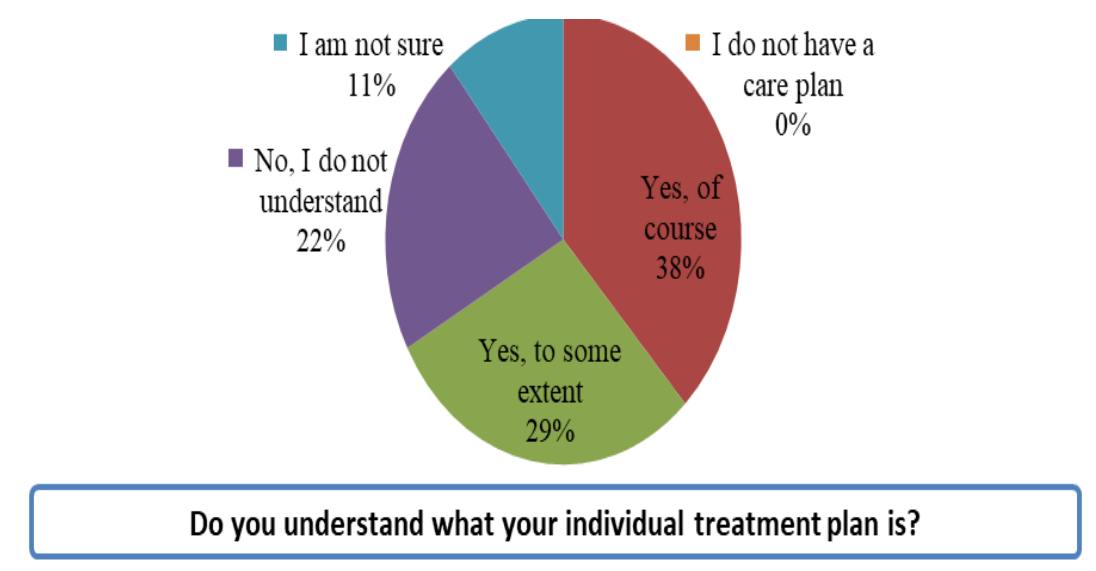

Figure 11 Information on the individual treatment plan

Regarding the open question, if they have something to add, some of the interviewees have expressed (Table 2):

Table 2 Respondents' opinions on the needs for change

- There is a lack of service from CMHC staff in the apartment.

- Due to the situation created by the pandemic of Covid-19 our concerns have increased and we would like a hotline where we can get psychological advice.

- Psychosocial staff should be added to have more complete coverage of the most frequent visits to the apartment by this service.

- Psychiatrists do not accept us without the recommendation of the family doctor, but for us who live in remote rural areas sometimes it is impossible to go to the family doctor due to the distance and lack of transport to get this recommendation.

- More information about the treatment

- The income we receive from the economic assistance scheme as incapable of work is so low that it is not enough for us for medical treatment and transportation.

- Employment opportunities because it is very difficult for us to get a job, no one hires us because of the disease we have.

- More facilities from the commission to benefit disability payment. 


\section{Conclusion and recommendations}

- Increase the number of professionals working in mental health services to meet the needs of the population for specialized care, as well as a better allocation of these resources in response to the need to improve access.

- To design and implement mental health promotion programs which would aim at raising public awareness, but also combating stigma and discrimination against people with mental health problems.

- Improving the system of planning and financing of social services in the community and implementation of bottom-up services, from the municipal to the district and central level.

- Due to the very important role of family members, it is highly recommended to provide the family with psychoeducation, counseling and their involvement in treatment and therapy.

- It is important to review the ways of treating MSCM patients. Treatment of patients should no longer prioritize only symptoms but functional rehabilitation, focusing on autonomy, independence, social rehabilitation and improving the quality of life, so the use of psychosocial interventions is advised.

- Develop plans and projects as well as review policies to create employment opportunities and facilities for individuals with mental health problems.

- Opening the Community Mental Health Centers in each city, they should not be at the county level, to create facilities in the transport of individuals for treatment and follow-up of each of them.

- Increasing the staff of Community Mental Health Centers in order to follow and monitor the beneficiaries in housing for individuals who have the inability to appear in these centers or for those individuals who have other concomitant diseases

\section{Compliance with ethical standards}

\section{Acknowledgments}

I would like to express my sincere gratitude to the supervisor Prof. Monika Bogdanova for the support and proper scientific guidance in the realization of this scientific work, as well as the staff of Community Mental Health Centers (CMHC), Elbasan, to provide the necessary conditions for conducting social work analysis.

\section{Disclosure of conflict of interest}

The authors declare that there is no conflict of interest for the presented study.

\section{Statement of informed consent}

Informed consent was obtained from all individual participants included in the study.

\section{References}

[1] Law no. 44/2012 "On mental health". Albania; 2012. Available from https://shendetesia.gov.al/wpcontent/uploads/2018/03/Ligji Nr.44 2012 per shendetin mendor.pdf

[2] The National Steering Committee for Mental Health. The Policy and the Operational Plan for Mental Health Services Development in Albania; 2003. Available from https://shendetesia.gov.al/wpcontent/uploads/2018/03/The Policy and the Operational Plan for M.H 2005 -2010.pdf

[3] Worls Health Organization (WHO). "Mental Health" - Action Plan 2013-2020; 2013. Available from https://apps.who.int/iris/bitstream/handle/10665/89966/9789241506021_eng.pdf;jsessionid=872F794EE7 4BBE0E03C6836626CB9578? sequence $=1$

[4] Alvis-Rizzo A. Aproximación teórica a la intervención psicosocial. Revista Poiésis. 2009; 17: 1-6. (Spanish). Available from https://www.funlam.edu.co/revistas/index.php/poiesis/article/view/189/178.

[5] Types of Psychosocial Treatments NAMI - National Alliance on Mental Illness; (C) 2021. Available from https://www.nami.org/About-Mental-Illness/Treatments/Psychosocial-Treatments

[6] Creswell JW. Research design: Qualitative, quantitative, and mixed methods approaches (2 ${ }^{\text {nd }}$ ed.). Thousand Oaks, CA: Sage. 2003 